\title{
Avaliação por Imagem de Formações Císticas no Joelho
}

\section{Imasing Evaluation of the Knee Cystic Formations}

\author{
Maria Carolina Guimarães ${ }^{(1)}$, Claudia Kazue Yamaguchi( ${ }^{(2)}$, Jamil Natour ${ }^{(3)}$, \\ Artur da Rocha Corrêa Fernandes ${ }^{(4)}$
}

\section{INTRODUÇÃO}

Formações císticas no joelho são relativamente comuns e freqüentemente são achados incidentais em exames de ressonância magnética $(\mathrm{RM})^{(1)}$. As manifestações clínicas dependem do tipo de lesão, localização, tamanho, efeito expansivo e relação com estruturas adjacentes. Os pacientes podem ser assintomáticos ou podem apresentar dor, massa palpável ou disfunção mecânica da articulação ${ }^{(2)}$. O cisto poplíteo ou de Baker é a formação cística mais comum que ocorre na região do joelho $^{(3)}$. Entretanto, o diagnóstico diferencial das formações císticas também deve incluir bolsas sinoviais, ganglions, recessos articulares e cistos meniscais, além de lesões que simulam cistos, tais como abscessos, hematomas, lesões vasculares (varizes e aneurismas poplíteos) e tumores benignos ou malignos, como os schwannomas, neurofibromas, mixomas, sarcoma sinovial, fibrohistiocitoma maligno, lipossarcoma ${ }^{(3,4)}$.

O estudo por imagem das formações císticas inclui o estudo radiológico convencional, ultra-som (US) e/ou $\mathrm{RM}^{(2,5)}$.

O estudo radiológico convencional ( $\mathrm{RX}$ ) é rápido, tem baixo custo relativo, sendo freqüentemente utilizado na avaliação inicial do joelho, possibilitando identificar aumento de partes moles, presença de corpos livres calcificados (Figura 1), calcificações periarticulares, sinais de artropatia, erosões ósseas e lesões destrutivas ${ }^{(2)}$.

O US é um bom método para avaliação de partes moles periarticulares, possibilitando a detecção de derrame articular, espessamento sinovial, corpos livres intra-articulares, coleções líquidas/formações císticas, lesões ligamentares e tendíneas. Entretanto, é importante reconhecer sua limitação na avaliação de meniscos, cartilagem e osso. Tem como principais vantagens a avaliação dinâmica, fácil comparação com o lado contralateral, possibilidade de correlação do local exato da dor e/ou tumoração com estruturas anatômicas, avaliação
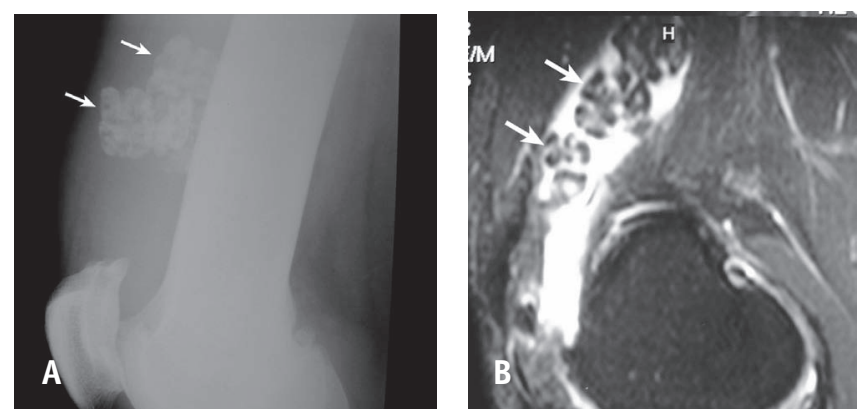

Figura 1 - (A) RX simples do joelho em perfil demonstrando calcificações (setas) anteriores à diáfise femoral, correspondendo a corpos livres intra-articulares. (B) RM, plano sagital, sequiência T2 com supressão do sinal da gordura (SPIR), evidenciando os corpos livres (setas) na bolsa suprapatelar.

através do Doppler, sendo, no entanto, indispensáveis para a realização de um exame adequado um equipamento de alta resolução, o conhecimento detalhado da anatomia regional e a experiência do operador ${ }^{(5)}$. No US, o aspecto típico do cisto é de uma formação delimitada com conteúdo anecóico/ hipoecóico. Porém, em alguns casos, pode haver dificuldade na diferenciação entre lesões císticas e sólidas ${ }^{(6)}$.

A RM oferece alto contraste de partes moles e capacidade multiplanar, permitindo determinar a localização precisa da formação cística, provável etiologia, relação com estruturas adjacentes, além de possibilitar a detecção de lesões associadas (meniscais, condrais, ligamentares) ${ }^{(3)}$. Na RM, a maioria das lesões císticas tem hipossinal nas seqüências ponderadas em Tl e hipersinal nas sequiências ponderadas em T2 ou STIR. Porém, deve-se ressaltar que estruturas com hipersinal em T2 não são necessariamente cistos. Se houver dúvida quanto à natureza da lesão (sólida ou cística) devido à localização, morfologia ou sinal incaracterísticos, o contraste endovenoso deve ser administrado, permitindo esta diferenciação. Isso porque as formações císticas não apresentam realce ou têm apenas um realce periférico, ao contrário das lesões sólidas que apresentam realce pelo meio de contraste ${ }^{(4)}$.

1. Médica Radiologista do Diagnósticos da América e da Clínica Miranda e Wiermann

2. Chefe do Setor Musculoesquelético do Serviço de Diagnóstico por Imagem do Hospital Santa Casa de Misericórdia de São Paulo e Médica Radiologista do Diagnósticos da América.

3. Professor Adjunto da Disciplina de Reumatologia da Universidade Federal de São Paulo (UNIFESP).

4. Professor Adjunto do Departamento de Diagnóstico por Imagem da UNIFESP e Médico Radiologista do Diagnósticos da América.

Endereço para correspondência: Artur da Rocha Corrêa Fernandes, DDI/UNIFESP, Rua Botucatu, 740, CEP 04023-900, São Paulo, SP, Brasil. 


\section{BOLSAS SINOVIAIS}

Bolsas sinoviais são estruturas revestidas por sinóvia que têm a função de reduzir a fricção entre estruturas ósseas e ligamentos ou tendões. Não são rotineiramente visualizadas em exames de imagem, pois em geral estão colabadas e com pouco líquido, podendo ser identificadas quando estão espessadas ou distendidas por líquido. Trauma, infecção e cristais são as causas mais comuns de bursite. Outras causas incluem artropatias inflamatórias crônicas, além de doenças proliferativas sinoviais (sinovite vilonodular pigmentada e osteocondromatose sinovial). Há várias bolsas ao redor do joelho, usualmente com localização e morfologia características que possibilitam o seu diagnóstico ${ }^{(4)}$. As bolsas podem ser divididas conforme a localização em anteriores [suprapatelar, subcutânea pré-patelar (Figura 2), subcutânea infrapatelar e infrapatelar profunda], mediais [anserina (Figura 3) e do ligamento colateral medial], póstero-mediais (gastrocnêmiosemimembranosa e do semimembranoso-ligamento colateral medial), laterais (iliotibial e do ligamento colateral-bíceps) ${ }^{(3)} \mathrm{e}$ posteriores (subtendíneas medial e lateral do gastrocnêmio) $)^{(1)}$. As bolsas suprapatelar e gastrocnêmio-semimembranosa, em geral, comunicam-se com o espaço articular e são consideradas, por alguns autores, como recessos articulares ${ }^{(4)}$. A bolsa ou recesso gastrocnêmio-semimembranoso, também conhecida como cisto poplíteo ou de Baker, tem como característica essencial para seu diagnóstico a presença de um colo localizado entre o tendão do semimembranoso e o ventre medial do músculo gastrocnêmio (Figura 4). A apresentação clínica mais freqüente é de massa indolor na face medial da fossa poplítea. Debris, hemorragia, corpos livres e proliferação sinovial podem estar presentes no cisto $^{(4)} \mathrm{e}$ a rotura aguda, clinicamente, pode simular tromboflebite ${ }^{(3)}$.

\section{RECESSOS ARTICULARES}

Recessos articulares são extensões diretas da cavidade articular que podem ser preenchidos por líquido. Há vários recessos ao redor do joelho, incluindo o recesso poplíteo e as fendas horizontal e vertical na gordura de $\operatorname{Hoffa}^{(4)}$.

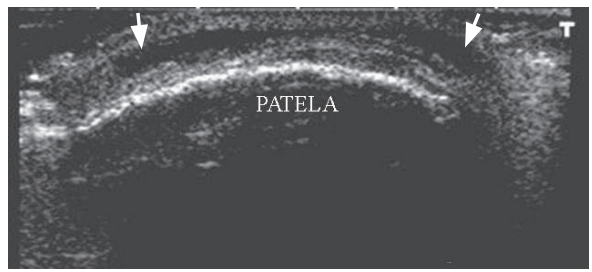

Figura 2 - Bursite pré-patelar. US, plano transversal evidenciando coleção líquida (setas) superficial à patela.
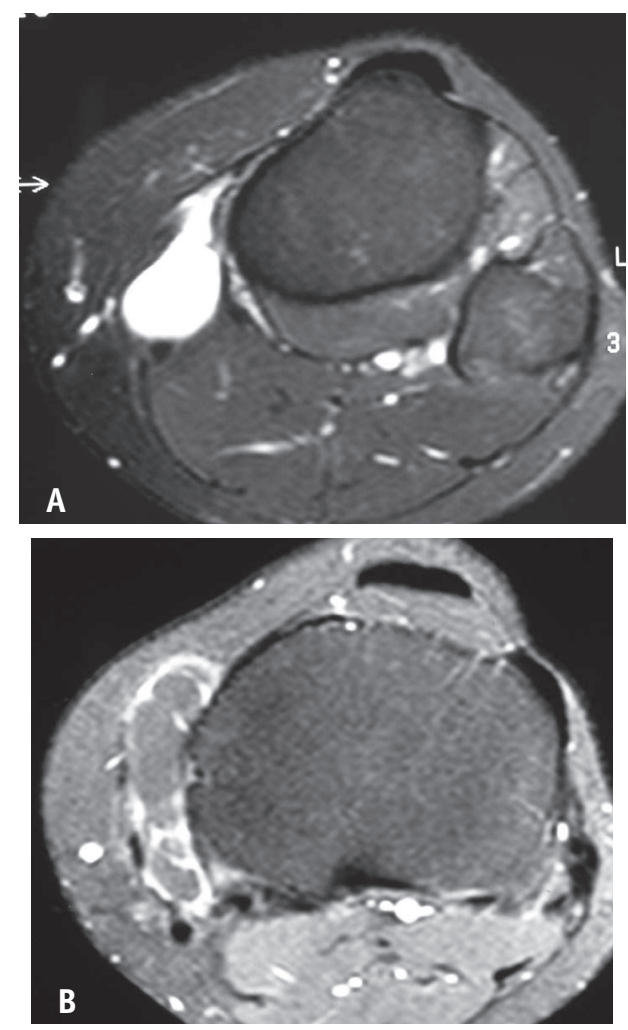

Figura 3 - Bursite anserina. RM, plano transversal (A) seqüência T2 SPIR evidenciando coleção líquida caracterizada por hipersinal (seta) na topografia da bursa anserina (da pata-de-ganso) situada profundamente à porção distal dos tendões do sartório, grácil e semitendíneo, adjacente à face ântero-medial da tíbia. (B) Seqüência T1 SPIR póscontraste evidenciando o realce periférico, confirmando a natureza cística da lesão.
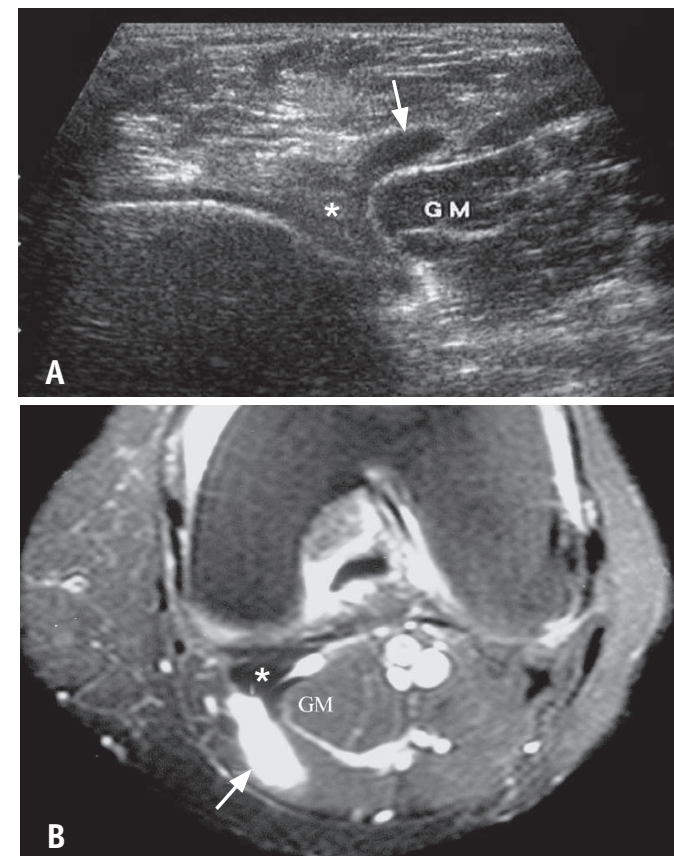

Figura 4 - Cisto de Baker. (A) US, plano transversal na região da fossa poplítea e (B) RM, seqüência T2 SPIR, plano transversal, evidenciando coleção líquida (seta) com colo entre o tendão do semimembranoso $\left(^{*}\right)$ e o ventre medial do músculo gastrocnêmio (GM). 


\section{CISTOS PARAMENISCAIS}

Cistos meniscais são coleções líquidas associadas a lesões meniscais, podem ser intra ou parameniscais. Os cistos parameniscais (Figura 5) originam-se pela extrusão de líquido através de lesão meniscal. Em geral, estão situados na região da interlinha articular e possuem comunicação com a lesão meniscal (freqüentemente, com componente horizontal). Podem erodir o osso subjacente. Os cistos laterais costumam ser menores, porém mais sintomáticos que os mediais. Os mediais podem distanciar-se da articulação, estando conectados apenas por um pedículo em continuidade com a lesão meniscal ${ }^{(3)}$. A proporção de cistos meniscais mediais e laterais é de aproximadamente $2: 1$, porém eles têm freqüência relativa semelhante, correspondendo a $7,7 \%$ das lesões do menisco lateral (ML) e a 7,8\% das lesões do menisco medial ${ }^{(7)}$.

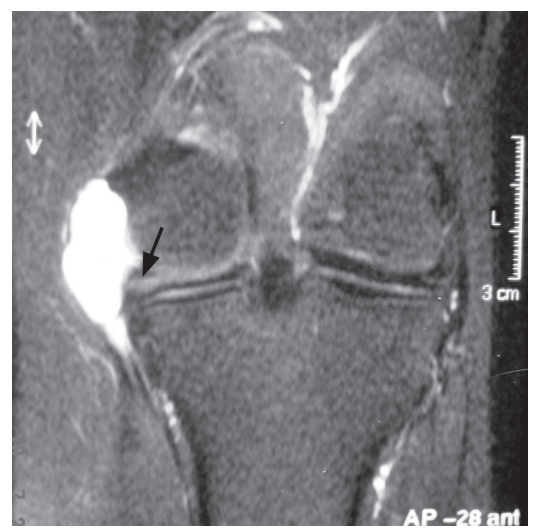

Figura 5 - Cisto parameniscal medial. RM, plano coronal, seqüência T2 SPIR, demonstrando formação cística $\left({ }^{*}\right)$ na região da interlinha articular medial comunicando-se com rotura meniscal (seta).

\section{GANGLIONS}

Ganglions são lesões benignas, com cápsula fibrosa e conteúdo mucinoso, têm predileção por localização periarticular, podem ser intra ou extra-articulares, intra-ósseos ou periosteais ${ }^{(3)}$.

Os ganglions extra-articulares encontram-se, em geral, em íntimo contato com a cápsula articular, bainhas tendíneas, tendões, ligamentos, músculos, nervos ou vasos ${ }^{(3,8)}$. Podem ser identificados em ganglions extra-articulares: canal de comunicação entre a articulação e o ganglion que pode ser contínuo ou descontínuo (66,7\%), edema perilesional (30\%), remodelação óssea (10\%) e comprometimento de nervo periférico $(10 \%)^{(9)}$. A maioria do ganglions extra-articulares é assintomática. São identificados como coleções líquidas bem delimitadas, lobuladas ou septadas (Figura 6) ${ }^{(3)}$. Os ganglions tibiofibulares proximais e ganglions intraneurais do nervo fibular comum podem estar associados à neuropatia caracterizada por parestesia/dor na face ântero-lateral da perna e dorsal do pé, seguida de fraqueza progressiva da musculatura anterior, progredindo para o pé caído ${ }^{(3)}$.

A doença adventicial cística é rara e consiste de lesão cística na adventícia de uma artéria ${ }^{(4)}$, que alguns autores defendem corresponder a um ganglion ${ }^{(8)}$. O quadro clínico é de claudicação intermitente em paciente jovem, geralmente sexo masculino e sem aterosclerose ${ }^{(4)}$.

Os ganglions intra-articulares podem ter sintomas inespecíficos como dor e/ou bloqueio articular que piora ao agachar, e, freqüentemente, estão localizados adjacente a um dos ligamentos cruzados ou à gordura infrapatelar profunda (Hoffa). Os ganglions relacionados ao ligamento cruzado posterior costumam ter aspecto multiloculado e localizam-se na sua superfície dorsal. Os do ligamento cruzado anterior (Figura 7), em geral, têm aspecto fusiforme e situam-se ao longo ou entre suas fibras, podendo inclusive simular lesão ligamentar na RM. Os ganglions da gordura Hoffa na maioria das vezes têm aspecto multilocular e localizam-se junto ao corno anterior do menisco lateral, devendo ser diferenciados de cistos parameniscais, por não se identificar rotura meniscal associada ${ }^{(3)}$.

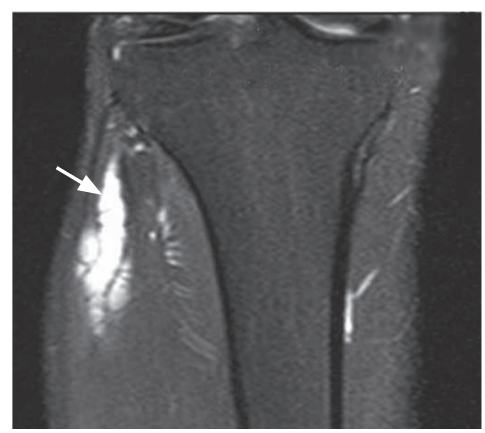

Figura 6 - Ganglion extra-articular. RM, plano coronal, seqüência T2 SPIR, demonstrando formação cística lobulada (seta) em planos musculares da face lateral da perna.

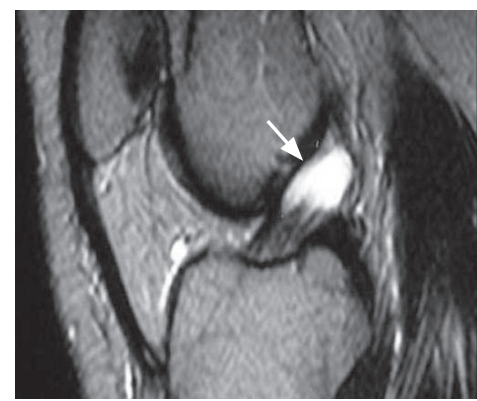

Figura 7 - Ganglion do ligamento cruzado anterior. RM, plano sagital, sequiência T2 SPIR, evidenciando coleção líquida alongada (seta) entre as fibras do ligamento cruzado anterior. 


\section{LESÕES QUE SIMULAM CISTOS}

Algumas entidades podem simular cistos, tais como aneurismas da artéria poplítea e varizes poplíteas, hematomas e abscessos, além de tumores benignos ou malignos [schwannomas e neurofibromas / mixomas / fibrohistiocitoma maligno / lipossarcoma / sarcoma sinovial (Figura 8)]. Nestes casos, a história clínica, aspectos de imagem e a utilização de meio de contraste na RM podem ajudar na caracterização destas lesões ${ }^{(3,4)}$.

\section{CONCLUSÃO}

Formações císticas ao redor do joelho são bastante comuns. Os pacientes podem ser assintomáticos ou apresentar sintomas clínicos que incluem, mais freqüentemente, massa palpável e dor. Os métodos por imagem associados a dados da história clínica e do exame físico possibilitam, na maioria das vezes, acrescentar informações relevantes para estabelecer o diagnóstico e a conduta. $\mathrm{O} \mathrm{RX}$ deve ser o estudo inicial, porém fornece poucas informações relativas às lesões císticas, devido ao baixo contraste de partes moles. O US é bastante útil para a avaliação das lesões císticas periarticulares, permitindo com freqüência a diferenciação entre lesões císticas e sólidas e o diagnóstico de cistos poplíteos, bursites, cistos meniscais e ganglions. A RM deve ser o método de escolha quando há suspeita de cistos intraarticulares, necessidade de determinar a localização precisa da formação cística e a relação com estruturas adjacentes, quando há suspeita de lesão intra-articular (meniscal, condral, ligamentar) associada e também quando há dúvida quanto à natureza da lesão (cística/sólida).

Declaramos a inexistência de conflitos de interesse.

\section{REFERÊNCIAS}

1. Tschirch FT, Schmid MR, Pfirrmann CW, Romero J, Hodler J, Zanetti M: Prevalence and size of meniscal cysts, ganglionic cysts, synovial cysts of the popliteal space, fluid-filled bursae, and other fluid collections in asymptomatic knees on MR imaging. AJR 180: 1431-6, 2003.

2. Beall DP, Ly JQ, Wolff JD, Sweet CF, Kirby AB, Murphy MP, Webb H, Fish JR: Cystic masses of the knee: magnetic resonance imaging findings. Curr Probl Diagn Radiol 34: 143-59, 2005.

3. McCarthy CL, McNally EG: The MRI appearance of cystic lesions around the knee. Skeletal Radiol 33: 187-209, 2004.

4. Morrison JL, Kaplan PA: Water on the knee: cysts, bursae, and recesses. Magn Reson Imaging Clin N Am 8: 349-70, 2000.
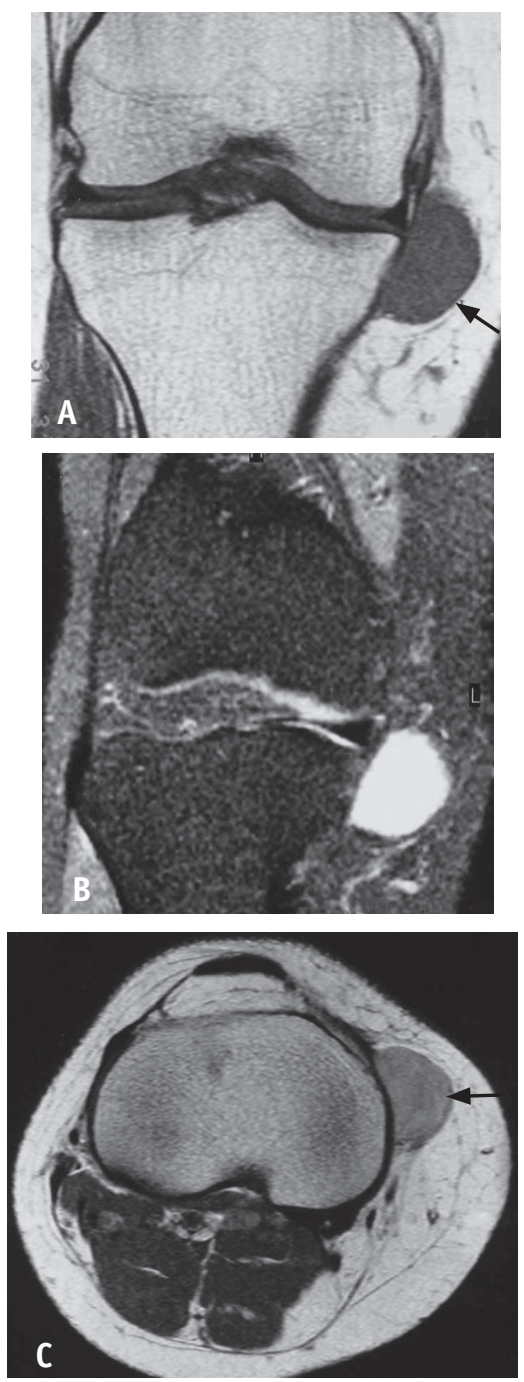

Figura 8 - Sarcoma sinovial. RM (A) plano coronal, seqüência T1 - formação ovalada bem delimitada (seta) com isossinal em relação à musculatura. (B) Plano coronal, sequiência T2 SPIR - a lesão apresenta hipersinal homogêneo, simulando cisto. (C) Plano transversal T1 pós-contraste - realce da lesão (seta) pelo meio de contraste, indicando sua natureza sólida.

5. Friedman L, Finlay K, Jurriaans E: Ultrasound of the knee. Skeletal Radiol 30: 361-77, 2001.

6. Holsbeeck MT, Introcaso JH: Muskuloskeletal Ultrasound. $2^{\underline{a}} \mathrm{ed}$. St. Louis: Mosby, 2001.

7. Campbell SE, Sanders TG, Morrison WB: MR imaging of meniscal cysts: incidence, location, and clinical significance. AJR Am J Roentgenol 177: 409-13, 2001.

8. Malghem J, Vande berg BC, Lebon C, Lecouvet FE, Maldague $\mathrm{BE}$ : Ganglion cysts of the knee: articular communication revealed by delayed radiography and CT after arthrography. AJR Am J Roentgenol 170: 1579-83, 1998.

9. Kim JY, Jung SA, Sung MS, Park YH, Kang YK: Extra-articular soft tissue ganglion cyst around the knee: focus on the associated findings. Eur Radiol 14: 106-11, 2004. 